University of Nebraska - Lincoln

DigitalCommons@University of Nebraska - Lincoln

U.S. Environmental Protection Agency Papers

U.S. Environmental Protection Agency

2002

\title{
A pharmacokinetic model for estimating exposure of Americans to dioxin-like compounds in the past, present, and future
}

Matthew Lorber

US Environmental Protection Agency, lorber.matthew@epa.gov

Follow this and additional works at: https://digitalcommons.unl.edu/usepapapers

Lorber, Matthew, "A pharmacokinetic model for estimating exposure of Americans to dioxin-like compounds in the past, present, and future" (2002). U.S. Environmental Protection Agency Papers. 104. https://digitalcommons.unl.edu/usepapapers/104

This Article is brought to you for free and open access by the U.S. Environmental Protection Agency at DigitalCommons@University of Nebraska - Lincoln. It has been accepted for inclusion in U.S. Environmental Protection Agency Papers by an authorized administrator of DigitalCommons@University of Nebraska - Lincoln. 


\title{
A pharmacokinetic model for estimating exposure of Americans to dioxin-like compounds in the past, present, and future
}

\author{
Matthew Lorber* \\ National Center for Environmental Assessment, Office of Research and Development, US Environmental Protection Agency, \\ 1200 Pennsylvania Ave, NW, Washington, DC, USA
}

Received 1 June 2001; accepted 5 October 2001

\begin{abstract}
Empirical evidence suggests that exposure of Americans to dioxin-like compounds was low during the early decades of the 20th century, then increased during the 1940s and 1950s, reaching a peak in the 1960s and 1970s, and progressively decreased to lower levels in the 1980s and 1990s. Such evidence includes dioxin analysis of carbon-dated sediment cores of lakes and rivers, preserved meat samples from different decades of the 20th century, and limited body burden measurements of dioxin-like compounds. Pinsky and Lorber (1998) summarized studies measuring 2,3,7,8-TCDD in blood and adipose tissue, and found a range of 10-20 pg/g (ppt) lipid during the 1970s, and 2-10 ppt lipid during the 1980s. This study reviews body burdens of dioxin toxic equivalents, TEQs, to find a range from approximately 50 to $80 \mathrm{ppt}$ lipid during the 1970s, 30-50 ppt lipid during the 1980s, and 10-20 ppt lipid during the 1990s (TEQs comprised of the 17 dioxin and furan congeners only). Pinsky and Lorber (1998) investigated historical exposure trends for 2,3,7,8-TCDD by using a single-compartment, first-order pharmacokinetic model. The current study extends this prior effort by modeling dioxin TEQs instead of the single compound, 2,3,7,8-TCDD. TEQs are modeled as though they were a single compound, in contrast to an approach where the individual dioxin and furan congeners are modeled separately. It was found that body burdens of TEQs during the 1970s, 1980s and 1990s could be modeled by assuming a historical dose which began the century at low levels of approximately 0.5 $\mathrm{pg}$ TEQ/ $\mathrm{kg} / \mathrm{day}$, rose during the middle decades of the 20th century to over $6 \mathrm{pg} T E Q / \mathrm{kg} / \mathrm{day}$, and declined to current levels of approximately $0.5 \mathrm{pg} \mathrm{TEQ} / \mathrm{kg} /$ day. Trends in individual and population body burdens of TEQs are also investigated using this PK modeling framework. A key uncertainty of this effort - assuming that TEQs behave as though they were a single compound - is discussed and analyzed. (C) 2002 Elsevier Science B.V. All rights reserved.
\end{abstract}

Keywords: Dioxin exposure; Pharmacokinetic modeling

\section{Introduction}

The first evidence that exposure to dioxin-like compounds may have been high during the middle

\footnotetext{
*Corresponding author. Tel.: +1-202-564-3243; fax: +1202-565-0078.

E-mail address: lorber.matthew@epa.gov (M. Lorber).
}

decades of the 20th century came with the analysis of dated sediment cores of lakes and rivers (Czuczwa and Hites, 1984; Czuczwa et al., 1985; Smith et al., 1992, 1993, 1995; Alcock et al., 1997). (The description, 'dioxin-like compounds,' typically includes seven polychlorinated dibenzo- $p$ dioxin congeners (abbreviated PCDDs), 10 


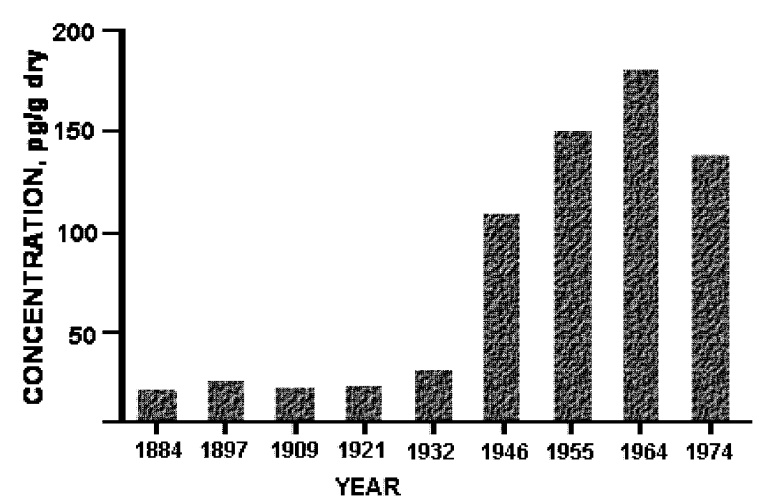

Fig. 1. Concentrations of total dioxins and furans in dated sediment cores from Beaver Lake in Washington (from Cleverly et al., 1996).

polychlorinated dibenzofuran congeners (PCDFs), and 12 co-planar polychlorinated biphenyl congeners (PCBs). This paper focuses only on the 17 PCDD/PCDF congeners.) These researchers found low concentrations in cores dated that back hundreds of years, and higher concentrations in core segments corresponding to the 1930s through the 1960s. Higher concentrations would have resulted from higher dioxin depositions to the land surface and water bodies. A lake core sediment study (Cleverly et al., 1996), comprised of cores from 11 pristine lakes around the United States, found results which were consistent with other studies finding higher concentrations corresponding to these mid-century years. The results from one of these lakes, Beaver Lake in Olympic Peninsula, Washington, is shown in Fig. 1.

While this might be reasonable evidence of more dioxin in the environment, it is not direct evidence of elevated exposures. To investigate the possibility of high past exposures, samples of preserved meat from different decades of the 20th century were collected and analyzed (Winters et al., 1998). Beef, pork, and poultry samples were obtained from such diverse sources as the USA's National Aeronautics and Space Agency, the National Smithsonian Museums, Army museums which retained soldier mess kits from as early as 1908, and Department of Agriculture Research Laboratories. The results of the analysis are shown in Fig. 2. Like the trend in sediment core studies, the early century samples had the lowest TEQ concentrations, including $0.34 \mathrm{pg}$ TEQ/g (ppt) lipid for the 1908 sample, $0.98 \mathrm{ppt}$ lipid for the 1945 sample, with the highest concentrations at 3.01 and 3.73 ppt lipid for samples from the 1960s. The two latest samples, both dated 1983, had lower concentrations again at 0.50 and $0.55 \mathrm{ppt}$ lipid. Current meat concentrations of TEQs are in the range of $0.8-1.0 \mathrm{ppt}$ TEQ lipid range based on national surveys on beef, pork, poultry, and milk (US EPA, 2000), as displayed in Fig. 2.

Recent studies also have documented declines in food concentrations from the 1980s to the 1990s. Harrison et al. (1998) used data from the United Kingdom's Total Diet Study of 1982 and 1992 to

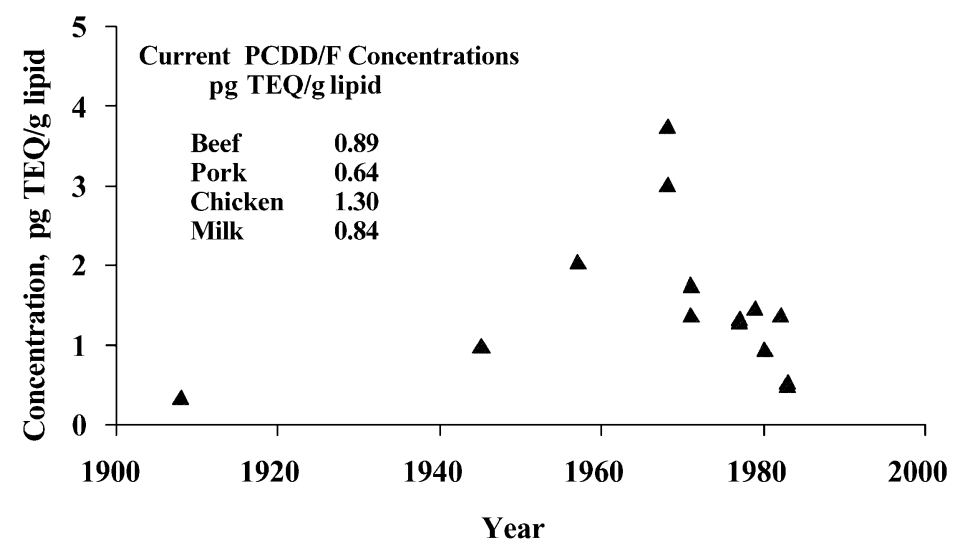

Fig. 2. TEQ concentrations in historical meat samples (from Winters et al., 1998). 
show how dietary intakes of dioxin-like compounds (PCDD/PCDF/PCBs) have dropped from $6.8 \mathrm{pg}$ TEQ $/ \mathrm{kg} /$ day to $2.4 \mathrm{pg}$ TEQ $/ \mathrm{kg} /$ day between 1982 and 1992. Fürst and Wilmers (1995) compared the levels of dioxins and furans found in German dairy products in 1990 with levels collected in 1994. Over the 4-year period, the mean TEQ concentration in milk fat decreased by almost $25 \%$ from 1.35 to 1.02 ppt.

The Environmental Protection Agency (EPA) reviewed this overall trend and concluded that elevations of dioxin in the environment beginning during the 1930s were the result of increases in industrial and combustion practices, production and use of phenolic compounds (e.g. pentachlorophenol), and energy production (e.g. coal and oil) (US EPA, 2000). Factors that led to the decline in environmental levels and exposures were identified as the Clean Air Act of 1970 and associated implementation of air pollution controls, the switch to unleaded automobile fuels and associated use of catalytic converters and reduction in halogenated scavenger fuel additives (remaining uses of leaded fuel include chain saws, logging machinery, and mowers), process changes at pulp and paper mills, and reductions in the manufacture and use of chlorinated phenolic intermediates and products (such as the ban of 2,4,5-T).

Pinsky and Lorber (1998) investigated this temporal trend for 2,3,7,8-tetrachlordibenzo- $p$-dioxin $(2,3,7,8$-TCDD, hereafter referred to as TCDD) using a single-compartment, first-order pharmacokinetic model. They summarized body burden measurements for this compound to find a range of 10-20 ppt lipid during the 1970s, and 2-10 ppt lipid during the 1980s. Their model assumed simplistically that all TCDD deposited into a single body reservoir of lipids and dissipated according to first-order kinetics. Their approach was to model populations which were demographically similar to the populations in these surveys. Specifically, individuals were modeled to be born during different years of the 20th century. At the year of the survey, their average predicted body burdens of TCDD were compared to the measured TCDD body burdens. Pinsky and Lorber assigned all but one of the model parameters using best estimates from the literature. Their first-order elimination rate function for TCDD, $k(t)$, was based on a model developed by Michalek et al. (1996), who modeled this parameter as a function of body fat fraction. The one parameter not assigned values based on the literature was a temporally varying dose. This daily dose, in units of pg TCDD $/ \mathrm{kg} /$ day, was 'calibrated' using Bayesian statistics, to arrive at a best-fit match between predictions and measurements of average population lipid concentrations of TCDD. Their best-fit dose, like the sediment cores and preserved meat samples, showed a steep rise from the 1940s through the 1960s, to peak at approximately 1970, and then to decline to low constant levels starting in the 1980s.

Van der Molen et al. (1996) conducted a very similar pharmacokinetic modeling exercise to study the TCDD body burdens of the Dutch population in the Netherlands. Their model was more complicated than the one employed by Pinsky and Lorber (1998): it had six compartments (blood, muscle, adipose tissue, bones, liver, and a compartment called remaining organs), but it was a first-order model, where the elimination of TCDD from the body occurred at a rate that was proportional to the TCDD concentration in the liver. Similar to Pinsky and Lorber (1998), they assumed that the lipid-based concentrations in each of the compartments was equal. They found that average body burdens of the Dutch population could best be duplicated by assuming a temporallyvarying dose as well. Citing sediment core data, they used a correction function, $F$, which was applied to a constant intake rate and related past intakes of TCDD to current intakes. Their $F$ function was bell-shaped with a peak value at 2.0 in 1965, a low value of 0.2 in 1920 , and values of 1.4 at 1980 and 0.6 in 1990.

This study is a continuance of the Pinsky and Lorber (1998) effort, only it models TEQs as though TEQs were a single compound. For purposes of this modeling effort, a TEQ concentration is comprised of seven PCDDs and 10 PCDFs. It is calculated as the sum of the toxically equivalent concentrations of each of the 17 congeners, where this toxically equivalent concentration is calculated as the concentration $\left(C_{i}\right)$ times a toxicity equivalency factor, or $\mathrm{TEF}_{i}$. A TEQ concentration is, therefore, $\sum \mathrm{TEF}_{i} C_{i}$. The TEFs used to calculate 
the TEQ are those recommended by the World Health Organization in 1998 (Van den Berg et al., 1998). Dioxin-like PCBs are not included in this analysis mainly because body burden concentrations of the dioxin-like PCBs are not available.

A review of TEQ body burden literature below is followed by a discussion of the model structure and parameterization. Unlike the modeling of Pinsky and Lorber (1998), two parameters of this model, the temporally varying dose and the rate of dissipation of TEQs from the body, were calibrated. The critical assumption of modeling TEQs, as though it were a single compound requiring calibration, is discussed below. The modeling framework, including the calibrations for TEQ dose and dissipation, is then used to study trends of exposure throughout the 20th century, and into the 21 st century.

\section{Review of body burden literature for TEQs}

The purpose of this section is to review dioxin body burden monitoring studies which have been conducted in the United States over the past few decades. Studies which sampled either blood or adipose tissue were compiled; studies on other matrices such as breast milk were not included. Lakind et al. (2000) cited several references where measurements of breast milk concentrations of lipophilic compounds (PCBs, DDE, DDT, PCDD/ PCDFs) were shown to decline during the course of lactation. Therefore, breast milk may not be a good indicator of body burden and is not included here. Other characteristics of studies included in this compilation are: (1) all or a toxicologically significant subset of the 17 PCDD/PCDFs were measured and individual-specific or overall study average concentrations of these congeners were available. In the few studies where less than the 17 congeners were available, it was determined (from other studies where they were all reported during the same time frame) that the available congeners made up $90 \%$ or higher of the TEQ concentration; (2) all results were reported on a lipid basis; (3) although this was not possible for all studies, it was desired to obtain data which had reported detection limits so that TEQ concentrations could be derived assuming non-detects
(NDs) equal one-half detection limit (1/2 DL). When DLs were not supplied, NDs were assumed to equal zero; (4) all measurements were on background populations. The first study described below included Vietnam veterans, non-Vietnam veterans, and civilians. All three groups were included in this analysis as the concentrations in the three were indistinguishable; the civilian population had, in fact, the highest concentrations. Another reason to include all three populations was that this was the only study available with the full suite of congener concentrations in the 1970s. Two other studies (Schecter et al., 1989, 1993) included blood samples taken from Vietnam veterans only. In both of them, small subsets of individuals appeared to have elevated concentrations of TCDD and TEQs. Congener-specific averages not including these individuals could be developed with the information in the articles, so these amended profiles were included in this compilation. (5) Only studies which sampled adult populations were included; data on children or infants were not included. Studies on 'average adult populations', which included demographic information, were comprised of approximately the same number of males and females and the average age was approximately 45. Studies on Vietnam veterans were all male populations, and one study sampling breast adipose tissue was on females alone.

Twelve studies were found for this compilation. A summary of the results from these studies is shown in Table 1.

Only one study could be found providing congener-specific concentrations from the 1970s. This study was undertaken by the US Department of veterans Affairs (DVA) and the EPA (Kang et al., 1991; US EPA, 1990), and the intent was to study tissue levels from Vietnam veterans compared to civilians. A total of 494 potential samples were identified from EPA's National Human Adipose Tissue Repository. These samples were dated from between 1972 and 1981, and they were from males born between 1936 and 1954. Searching military records verified that 134 of the 494 samples were from veterans, 40 of whom served in Vietnam. They selected all of these 40, as well as 80 of the remaining 94 veterans who had not served in 
Table 1

Summary of studies with body burden data of dioxins and furans

\begin{tabular}{|c|c|c|c|c|}
\hline Year & $\begin{array}{l}\text { Mean TEQ, } \\
\mathrm{pg} / \mathrm{g} \text { lipid }\end{array}$ & $N$ & Ages & Reference; Location \\
\hline 1972 & 87 & 7 & \multirow[t]{10}{*}{$18-45$} & \multirow{10}{*}{$\begin{array}{l}\text { Kang et al., 1991; USEPA, 1990. Vietnam veterans, } \\
\text { non-Vietnam veterans and Civilians. }\end{array}$} \\
\hline 1973 & 89 & 14 & & \\
\hline 1974 & 70 & 14 & & \\
\hline 1975 & 68 & 14 & & \\
\hline 1976 & 129 & 5 & & \\
\hline 1977 & 69 & 17 & & \\
\hline 1978 & 69 & 17 & & \\
\hline 1979 & 67 & 22 & & \\
\hline 1980 & 55 & 42 & & \\
\hline 1981 & 54 & 26 & & \\
\hline 1983 & 34 & 4 & NA & Schecter et al., 1986; Binghamton, NY \\
\hline 1985 & 47 & 35 & $\begin{array}{l}\bar{x}=43 \\
(21-88)\end{array}$ & Graham et al., 1986; St. Louis, MO \\
\hline 1986 & 31 & 4 & $\begin{array}{l}\bar{x}=34 \\
(19-55)\end{array}$ & Patterson et al., 1994; Atlanta, GA \\
\hline 1987 & $\begin{array}{l}\text { overall: } 37 \\
\text { 15-44: } 27.5 \\
>45: 53.4\end{array}$ & 666 & NA & Orban et al., 1994; EPA,1991 \\
\hline 1988 & 30 & 26 & NA & Schecter et al., 1989; Massachusetts \\
\hline 1988 & 37 & 57 & $\begin{array}{l}\bar{x} \sim 50 \\
(12-88)\end{array}$ & $\begin{array}{l}\text { Stanley et al., 1989; San Francisco and Los } \\
\text { Angeles, CA }\end{array}$ \\
\hline 1989 & 50 & 100 & NA & Schecter, 1991; Syracuse, NY \\
\hline 1991 & 29 & 44 & $\begin{array}{l}\bar{x}=48 \\
(41-66)\end{array}$ & Schecter et al., 1993; Michigan Vietnam veterans \\
\hline 1996 & 32 & 100 & NA & Schecter et al., 1997; Binghamton, NY \\
\hline 1996 & 20 & 316 & $\begin{array}{l}\bar{x}=45 \\
(20-70)\end{array}$ & $\begin{array}{l}\text { Personal communication from D. Patterson, } \\
\text { Center for Disease Control, Atlanta, GA, to M. } \\
\text { Lorber, US EPA, Washington, DC. April, 2000; } \\
\text { background populations from site-specific } \\
\text { studies in MO, OR, WS, AK and NC. }\end{array}$ \\
\hline 1998 & 25 & 45 & $\begin{array}{l}\bar{x}=45 \\
(28-67)\end{array}$ & Petreas et al. 2000; San Francisco, CA \\
\hline
\end{tabular}

Vietnam (these 80 selected randomly from the population of 94). They matched each of the 40 veterans with two civilians in terms of age and sex from the potential population of 494. The final population of this study was, therefore, 200 individuals: 40 veterans serving in Vietnam, 80 nonVietnam veterans and 80 civilians. Five samples were discarded as inappropriate (insufficient lipid amounts, insufficient data regarding military status), for a final sample count of 195 .
While a comprehensive set of data, this was not a good representation of an average American population because the oldest individual was less than 46 years (the last year sampled, 1981, minus the earliest birth date, 1936), and they were all males. Still, it was the only data set from these years that measured all the 17 PCDD/PCDFs, and results do suggest that these individuals were not influenced by unique high exposures. The results from these three sample sets were indistinguishable 
- TEQ concentrations were 71.9, 65.4 and 72.0 $\mathrm{pg} / \mathrm{g}$ lipid for the Vietnam veterans, the nonVietnam veterans, and the civilians, respectively. The TCDD concentrations followed the same trend, with concentrations of 13.4, 12.5 and 15.8 for the same three groups. For this reason, these study populations were merged for further analysis here. These full study summaries can be considered to represent the years 1972-1981 for this limited male population.

The results from this EPA/DVA study supplied in US EPA (1990) did not indicate the year in which each of the samples were taken. This information was retrieved (by personal communication, J. Remmers, Office of Prevention, Pesticides, and Toxic Substances, US EPA, to M. Lorber, Office of Research and Development, US EPA, 2000), which allowed for the year-by-year compilations shown in Table 1. Only 178 of the 195 samples could be identified by year of sample collection.

As seen in Table 1, there appears to be a clear trend, with concentrations declining from approximately $80 \mathrm{ppt}$ TEQ to approximately $50 \mathrm{ppt}$ TEQ between 1972 and 1981. The five samples averaging 129 ppt TEQ in 1976 would appear to be anomalous. There were other samples with concentrations above $100 \mathrm{ppt}$, such as a sample at 151 ppt TEQ from 1981, at 166 ppt from 1978, and at 179 ppt from 1973, but four of the five samples in 1976 ranged from 99 to 215 ppt TEQ. There is no reason to believe that the high average in 1976 is indicative of any unique exposure for that year.

There were seven studies from the 1980s. The most prominent study from that decade was the National Human Adipose Tissue Survey of 1987 (NHATS '87) (Orban et al., 1994; US EPA, 1991). This study was undertaken, in part, to compare with a very similarly designed survey in 1982, NHATS ' 82 . For both surveys, composite samples of adipose tissue from individuals characteristic of average background conditions were analyzed for the full suite of dioxin and furan congeners. NHATS ' 82 was not included in this temporal trend compilation because there appears to have been unexplained high findings of 1,2,3,7,8PCDD, and given that this congener has a TEF of 1.0, the resulting TEQ concentrations were simply out of bounds. Specifically, this study found a concentration of $125.0 \mathrm{ppt}$ for 1,2,3,7,8-PCDD for the age group, $15-45$, and the overall average 1,2,3,7,8-PCDD concentration for NHATS ' 82 at $73.6 \mathrm{ppt}$ (which includes all three age groups, $0_{-}$ $14,15-45$, and $>45$ years) is itself significantly higher than that ever found elsewhere.

Results from 38 of the 48 composite samples used from NHATS ' 87 consisted of two age groups: $15-45$ and $>45$ years. The 10 composites representing the $<15$ age group were not included. These 38 samples represented 666 individuals. According to the 1980 census, these two groups comprised 46 and $31 \%$ of the population. Average congener concentrations for these age groups were weighted to get the adult average concentration of 37 ppt TEQ shown in Table 1. Like other studies, there appears to be an age trend, with the older set having an average of 53 ppt TEQ, while the younger age range had an average almost half that at 28 ppt TEQ.

Another significant study by Graham et al. (1986) reported on the analysis of adipose tissues from autopsy patients who were not hospitalized but who had died suddenly or violently during 1985. They listed age and sex in the tabular summary of results from 35 individuals. Of these individuals, 16 were male and 19 were female, and the age range was from 21 to 88 , with an average age of 43 . The average TEQ concentration from this population was $47 \mathrm{ppt}$ lipid. There is a clear age trend in this data set, which is examined later in this paper, with concentrations ranging from less than 20 ppt TEQ lipid for the youngest sampled individual to over 100 ppt TEQ lipid for the oldest sampled individual. The highest sample was approximately 140 ppt TEQ lipid for a 60year-old individual.

Two studies, one from the 1980s and one from the 1990s, required screening out of samples from Vietnam veterans which were high and appear to have been influenced by exposure to Agent Orange. In the first study (Schecter et al., 1989), blood was collected from 28 Vietnam veterans. Of the 28 sampled, it appeared as though two had been exposed to Agent Orange in Vietnam or to another source of TCDD. The concentration of this congener in their blood was 34 and 29 ppt 
lipid, and the TEQ concentrations were 54 and 62 ppt lipid. The other congeners in the blood of these two individuals did not appear elevated. For the other 26 individuals, the average TCDD concentration was $4.8 \mathrm{ppt}$ and the average TEQ concentration was $29.6 \mathrm{ppt}$ lipid. These results were the ones used in this compilation. In the other study (Schecter et al., 1993), blood was collected from 50 Vietnam veterans in 1991. Levels of TCDD and other dioxins were elevated in six of these 50 Vietnam veterans. The average TEQ concentration in these six individuals was 85 ppt lipid. The average TEQ concentration in the remaining individuals was much lower at $29.1 \mathrm{ppt}$ lipid. This population was used in this study.

Another study with a reasonably large population was undertaken by the California Air Resources Board for the purpose of determining a preliminary estimate of the body burden levels of dioxins and furans in the California population so that future efforts evaluating the impact of specific air sources can use the knowledge gained in terms of survey design, implementation, and analysis, as well as the background levels found (Stanley et al., 1989). A total of 57 adipose tissue samples were taken from an initial target population of 60 surgical patients who were in surgery for reasons other than cancer. The average age of the patients was approximately 50 years. The average concentration found was $31 \mathrm{ppt}$. Like other studies, an age trend was found, with a finding of $<10 \mathrm{ppt}$ TEQ lipid for the youngest individuals sampled, approximately 21 years old, to approximately 80 ppt TEQ lipid for an individual over 60 years old.

The most significant of the four studies found representing the 1990s was supplied to the US EPA by the Centers for Disease Control (personal communication from D. Patterson, Center for Disease Control, Atlanta, GA, USA, to M. Lorber, US EPA, Washington, DC, USA, April, 2000). This extensive compilation was used by the EPA to represent average background body burdens in the United States during the mid- to latter 1990s in their draft Dioxin Reassessment (US EPA, 2000). The compilation consists of results from the background populations of six site-specific studies: Manchester, Missouri $(n=61)$; Times Beach, Missouri (MO) $(n=67)$; Jacksonville,
Arkansas (AK) $(n=57)$; Oregon (OR) $(n=9)$; Wisconsin (WI) $(n=93)$; and North Carolina (NC) $(n=29)$. The average TEQ concentration from this compilation is $20 \mathrm{ppt}$ lipid. The age of the individuals sampled were available from 214 individuals located in Missouri, Arkansas, and North Carolina. The average age was 45 years, with a range of 20-70 years. While an age trend is evident, which will be discussed later in the paper, it does appear as though that the trend is much less marked as compared to earlier years.

The most recent data available was from Petreas et al. (2000), who presented a summary of results of analysis of breast tissue samples taken from women undergoing breast surgery during 1998. Unlike the Vietnam veteran studies, this was the only study comprised only of women. These 45 women comprised the control group in a breast cancer case-control study in the San Francisco Bay area. Specific results from each individual were not available in Petreas et al. (2000), but were supplied by personal communication (personal communication from M. Petreas, Hazardous Material Laboratory, California EPA, to M. Lorber, US EPA, 2000). The average age of these women was 45 , with a range of $28-67$. The average TEQ concentration was 25 ppt lipid.

Remaining studies include two studies (Schecter et al., 1986; Patterson et al., 1994) which involved a small number of individual samples in Binghamton, NY and Atlanta, GA, a pooled sample of blood from 100 individuals in the Syracuse, New York Red Cross Blood Bank (Schecter, 1991), and a second pooled (100 individuals again) blood sample from a hospital laboratory in Binghamton, NY (Schecter et al., 1997).

\section{Pharmacokinetic modeling methods}

\subsection{The model}

The single compartment, first-order PK model is given by:

$$
\begin{aligned}
& \frac{\mathrm{d} a(t)}{\mathrm{d} t}=f D(t)-k(t) a(t) \\
& c(t)=\frac{a(t)}{1000 V(t)}
\end{aligned}
$$




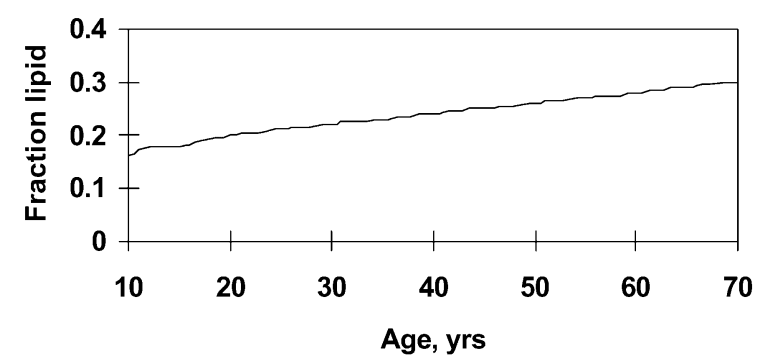

Fig. 3. Fraction of total body fat assumed for an individual in the pharmacokinetic modeling (approximation of average male and female trends, from US EPA, 1997).

where $a(t)$ is the amount of TEQ in lipid (pg) during year $t$ of a person's life; $c(t)$ is the concentration of TEQ in lipid ( $\mathrm{pg} / \mathrm{g}) ; D(t)$ is the annual exposure dose of TEQ (pg/year), calculated as $365 \times e(t) \times w(t)$ where $e(t)$ is the daily exposure (pg TEQ/kg/day) and $w(t)$ is the body weight $(\mathrm{kg}) ; V(t)$ is the lipid weight $(\mathrm{kg})$, calculated as the $w(t) \times \operatorname{bff}(t)$ where $\operatorname{bff}(t)$ is the body fat fraction (unitless); $k(t)$ is the elimination rate (years $\left.{ }^{-1}\right) ; f$ is the constant fraction of dose absorbed into the lipid compartment; and $t$ describes the year in an individual's life (year).

The fraction absorbed, $f$, is the only constant in this model, is set at 0.8 , reflecting the assumption that nearly all dioxin exposure is through animal fat consumption and other studies have shown high absorption by this pathway (US EPA, 2000). Statistical data on body weight and body fat fraction as a function of age for males and females were averaged and used in this exercise. This data is from EPA's Exposure Factors Handbook (US EPA, 1997). Figs. 3 and 4 show the assumptions of body weight, $w(t)$, and body fat fraction, $\operatorname{bff}(t)$, as a function of a person's age. The volume of body lipids, $V(t)$, is calculated as the product of body weight and body fat fraction.

\subsection{The elimination rate function for TEQs}

The first-order elimination rate, $k(t)$, was allowed to vary as a person aged and was calibrated for TEQs as though they behaved as a single compound. Fig. 5 shows three functions for the first-order elimination rate constant, $k(t)$, as a

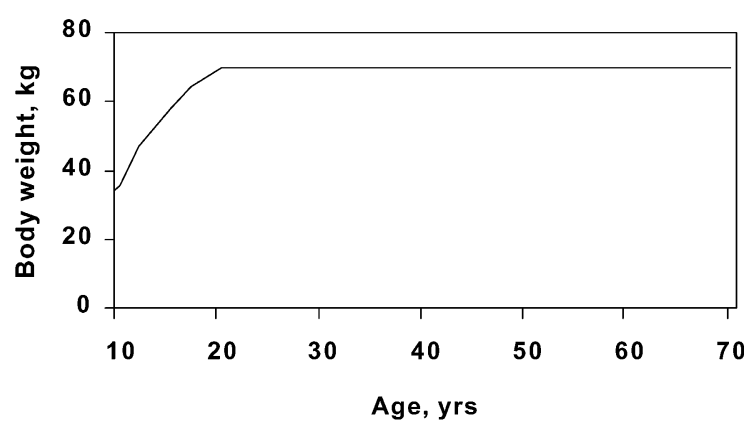

Fig. 4. The total body weight assumed for an individual in the pharmacokinetic modeling (approximation of average male and female trends, from US EPA, 1997).

function of age, including the function for TEQs calibrated in this effort [identified as (a) in Fig. 5], a modeled function for TCDD in Van der Molen et al. (1998) [curve (b)], and a function for TCDD that is based on a relationship between $k(t)$ and body fat fraction [curve (c)].

Pinsky and Lorber (1998) re-performed an analysis conducted by Michalek et al. (1996) and arrived at a relationship showing that the firstorder elimination rate, $k$, of TCDD is a function of body fat fraction: as body fat increases, the elimination rate decreases (equivalently, the elimination half-life increases). This analysis was conducted by using blood concentration data taken over time on Vietnam veterans with high TCDD body burdens. This longitudinal database was somewhat limited since it only included men and



Fig. 5. Three functions giving the half-life as a function of age, including: (a) calibrated TEQ function assumed in this effort; (b) TCDD function in Van der Molen et al. (1996); and (c) TCDD function in Pinsky and Lorber (1998). 
did not involve men with a wide age range. Still, it demonstrated the relationship between body fat fraction and the rate of TCDD dissipation, and allowed for this relationship in Pinsky and Lorber (1998):

$k(t)=k_{0}+k_{1}(F(t)-25)$

where $k_{0}$ is the elimination rate at $25 \%$ body fat (years ${ }^{-1}$ ); $k_{1}$ is a constant reflecting the change in elimination rate with percentage body fat (years ${ }^{-1}$ ); and $F(t)$ is the percentage body fat at time $t$, which equals $100 \times V(t) / W(t)$. Pinsky and Lorber (1998) derived estimates of 0.0775 for $k_{0}$ and -0.00313 for $k_{1}$. For comparison, the estimates reported in Michalek et al. (1996) were 0.0665 for $k_{0}$ and -0.00314 for $k_{1}$. When this relationship is combined with the body fat fraction function shown in Fig. 4, the $k(t)$ vs. age function shown in Fig. 5c emerges. The Van der Molen et al. (1998) half-life function, as shown in Fig. 5b, was derived using an earlier toxicokinetic model he had developed (Van der Molen et al., 1996) and the same Vietnam veteran data. The overall elimination rate is given as the product of a specific elimination rate, $k$, and $X$, the ratio between the lipid-weight of the liver and the total body lipid-weight. In their exercise, Van der Molen et al. (1998) developed values for all model parameters except this specific elimination rate, which was curve fit to this Vietnam veteran data. The rise in their half-life function reflects the change in $X$ as an individual ages.

All three relationships suggest that the half-life of these compounds increase as a person ages. For example, the half-lives at ages 10 and 70 are 6.6 and 11.2, respectively, for TCDD according to the relationship developed by Pinsky and Lorber (1998), 5 and 13.8 for TCDD as developed by Van der Molen et al. (1998), and 6.9 and 18.5 for TEQs as calibrated in this effort.

It would have been preferable to first assign a function to the elimination rate, $k(t)$, for TEQs, and then calibrate solely on the dose function, as was done in Pinsky and Lorber (1998). However, appropriate longitudinal data for TEQ body burdens, as was available for TCDD from the Vietnam veterans, was not available for this effort. Van der Molen et al. (2000) located congener-specific data on an occupationally exposed cohort who had been exposed to high levels of dioxins and furans for a period of several years, and had been measured two or three times after exposure. It may be possible at some time to use this longitudinal data to develop congener-specific elimination rate/age functions such as those developed for TCDD as shown in Fig. 5. Van der Molen et al. (2000) developed two sets of congener-specific singlevalue elimination half-lives from this data - one based on longitudinal data and the other based on cross-sectional data, and found these two estimates to be very similar.

Table 2 lists Van der Molen's (2000) elimination rates and half-lives derived for a 49 -year-old person, i.e. the average person from the cross-sectional data, and the same two elimination parameters for the 17 congeners as provided in Flesch-Janys et al. (1996). Column 1 in Table 2 provides the fraction that each congener provides to the overall current intake dose of TEQ, as developed by EPA (US EPA, 2000). For example, 10\% of the current total daily intake of TEQs is provided by TCDD. This information can be used to derive a doseweighted average elimination rate and/or half-life for a TEQ dose. This would be a first approximation suggestive of the rate that TEQs would be eliminated. The TEQ dose-weighted half-life and elimination rate are easily estimated as $\sum(F i \times H L i)$ and $\sum(F i \times K i)$, where $F i$ are the fractional intakes for congener $i, H L i$ are the congener-specific half-lives, and $K i$ are the congener-specific elimination rates. As seen in Table 2 , the TCDD half-life and elimination rate constant appears to be approximately 7.4 years and 0.094 year $^{-1}$, respectively, while the TEQ dose-weighted terms are in the range of 9.8-12.5 years and $0.072-0.083$ year $^{-1}$. An individual half-life and elimination rate are related as: $H L=0.693 / \mathrm{K}$. However, the dose-weighted half-life and elimination rate are not directly related - one cannot derive the dose-weighted half-life directly from the dose-weighted elimination rate by this equivalence: $\sum(F i \times H L i) \neq 0.693 / \sum(F i \times K i)$. The term on the right hand side of this equation can also be written as, $0.693 / \sum[F i \times(0.693 / H L i)]$, which is simplified as $1 / \sum(F i / H L i)$, and this is not mathematically equivalent to $\sum(F i \times H L i)$. This dispar- 
Table 2

Dose-weighted estimation of a first-order elimination rate for TEQs

\begin{tabular}{|c|c|c|c|c|c|}
\hline \multirow[t]{2}{*}{ Congener } & \multirow{2}{*}{$\begin{array}{l}\text { Fraction TEQ } \\
\text { in dose } \mathrm{e}^{\mathrm{a}}\end{array}$} & \multicolumn{2}{|c|}{ Flesch-Janys et al. (1996) } & \multicolumn{2}{|c|}{ Van Der Molen et al. (2000) } \\
\hline & & $k$, year ${ }^{-1}$ & half-life, years & $k$, year $^{-1}$ & half-life, years \\
\hline 2378-TCDD & 0.1 & 0.096 & 7.2 & 0.091 & 7.6 \\
\hline 12378-PCDD & 0.33 & 0.044 & 15.7 & 0.062 & 11.1 \\
\hline 123478-HxCDD & 0.034 & 0.083 & 8.4 & 0.061 & 11.3 \\
\hline 123678-HxCDD & 0.12 & 0.053 & 13.1 & 0.06 & 11.5 \\
\hline 123789-HxCDD & 0.044 & 0.141 & 4.9 & 0.104 & 6.6 \\
\hline 1234678-HpCDD & 0.041 & 0.187 & 3.7 & 0.081 & 8.5 \\
\hline OCDD & 0.001 & 0.103 & 6.7 & 0.126 & 5.5 \\
\hline 2378-TCDF & 0.022 & 0.096 & 7.2 & 0.508 & 1.4 \\
\hline 12378-PCDF & 0.01 & 0.044 & 15.7 & 0.246 & 2.8 \\
\hline 23478-PCDF & 0.17 & 0.035 & 19.6 & 0.071 & 9.7 \\
\hline 123478-HxCDF & 0.04 & 0.112 & 6.2 & 0.092 & 7.5 \\
\hline 123678-HxCDF & 0.035 & 0.116 & 6 & 0.03 & 23.2 \\
\hline 123789-HxCDF & 0.025 & 0.116 & 6 & NA & NA \\
\hline 234678-HxCDF & 0.019 & 0.119 & 5.8 & 0.197 & 3.5 \\
\hline 1234678-HpCDF & 0.01 & 0.231 & 3 & 0.143 & 4.8 \\
\hline 1234789-HpCDF & 0.0019 & 0.216 & 3.2 & 0.069 & 10 \\
\hline OCDF & 0 & 0.103 & 6.7 & 1.018 & 0.7 \\
\hline \multicolumn{2}{|c|}{ TEQ-weighted results } & 0.072 & 12.5 & 0.083 & 9.8 \\
\hline
\end{tabular}

${ }^{a}$ Defined as the fraction of the total TEQ dose that comes from each congener, from US EPA (2000).

ity is similar to the difference between a harmonic mean and a simple mean. Still, looked at either way, the TEQ dose-weighted disappearance terms imply more persistence in the body as compared to the disappearance terms for TCDD.

Besides a lack of elimination/age functions for individual congeners, use of a single elimination rate for the complex mixture of chemicals that comprise a TEQ concentration is, strictly speaking, invalid. For a given initial body burden of 17 PCDD/PCDF congeners, the elimination rates for the congeners will be different such that, after time, different profiles of the congeners will emerge. Over time, the overall half-life of the changing TEQ body burden profile will become dominated by the more slowly eliminated congeners.

This is easily demonstrated using information provided in Table 2. The fractional terms describing the contribution of total TEQ provided by each congener (Column 1 of Table 2) were used to derive a hypothetical initial body burden profile of the 17 congeners comprising a TEQ mixture. Each congener then dissipated according to first-order kinetics, using the Flesch-Janys half-lives provided in the second column of Table 2. It was found that the first half-life of this initial body burden occurred after 11 years, and that the second halflife (when the initial TEQ body burden was $25 \%$ of its original concentration) 14 years later. For this reason alone, modeling TEQs as though they were a single compound must be thought of as a simplification adopted here for the purposes of modeling and better understanding past exposures and the implications of past and present exposures on future body burdens of TEQs.

\subsection{Calibration algorithm}

Individuals are modeled from birth until 70 years of age. While breast feeding can result in a large initial increase in an infant's body burden of dioxin TEQs, EPA showed how the overall body burdens of breast-fed vs. formula-fed infants begin to merge between ages 15 and 20 (US EPA, 2000). Therefore, predictions of average adult concentrations will not be significantly affected by assumptions regarding exposures during infancy and 
childhood (although lifetime exposure calculations and other assessments are, of course, affected by high exposures during childhood). For this exercise, formula feeding is assumed, and childhood doses of dioxins, like adult doses, are modeled as the calibrated dose, in units of pg TEQ $/ \mathrm{kg} /$ day, times body weight, in $\mathrm{kg}$.

The daily dose term for year $t$ of an individuals life, $e(t)$, used for the calculation of the annual dose term, $D(t)$, is calibrated as was the $k(t)$. The calibration strategy was to have individuals born in 5-year increments starting in 1860 . Their body burdens were modeled using a 1-year time step until they are 70 years old. The 'modeled' adult population average TEQ for a given year after 1930 (in 5-year increments, such as 1930, 1935, etc.) was calculated as the average of TEQ concentrations predicted for 11 individuals, aged 2070 , with an average age of 45 .

There was no rigorous attempt to find a 'best fit' of model predictions and population measurements, nor was there specific attempts to match the demographics of the measured populations. This information was used to assist in the direction of the calibration:

(1) The current average adult dose of TEQs as developed by EPA is $0.65 \mathrm{pg}$ TEQ/g (US EPA, 2000); (2) the time of the peak dose was in the mid to latter 1960s, which is supported by the modeling efforts of Pinsky and Lorber (1998) and Van der Molen et al. (1996); and (3) the TEQ exposure at this peak might be in the range of 3-5 times higher than current exposures. This is approximately the ratio between current and mid1960s meat concentrations in the historical meat survey, and also in the range of the ' $F$ ' function of Van der Molen et al. (1996). However, the peak TCDD dose modeled by Pinsky and Lorber (1998) is more than 20 times higher than the current dose.

Early and late century TEQ doses were set at $0.50 \mathrm{pg}$ TEQ $/ \mathrm{kg} /$ day. This late century assignment is reasonably similar to the $0.65 \mathrm{pg}$ TEQ $/ \mathrm{kg} / \mathrm{day}$ background dose developed by the EPA (US EPA, 2000). There is no information on early century and pre-20th century doses, so for the sake of simplicity, the same constant dose of $0.50 \mathrm{pg}$ TEQ $/ \mathrm{kg} /$ day was assumed. A rise in dose was assumed to begin in 1930 , to peak at 1970 , and

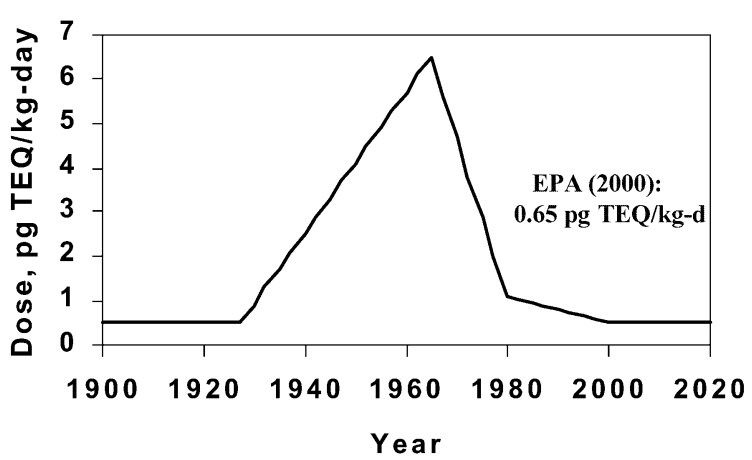

Fig. 6. Calibrated TEQ intake dose function for this effort. Noted is US EPA (2000) estimate of current intake dose of $0.65 \mathrm{pg}$ TEQ/kg/day.

then to decline to this constant $0.50 \mathrm{pg}$ TEQ $/ \mathrm{kg} /$ day value by the end of the century. A first set of calibration runs used the TCDD elimination rate function shown as curve (c) in Fig. 5. It was found, however, that the mid-century doses of TEQs with this TCDD elimination rate had risen to very high values, well over $10 \mathrm{pg}$ TEQ $/ \mathrm{kg} /$ day, much higher than the 3:5 ratio to current dose that seems reasonable from available data. It was at this time that a $k(t)$ function showing slower elimination as the individual aged was adopted. Then a calibrated dose rising to just above $6.0 \mathrm{pg}$ $\mathrm{TEQ} / \mathrm{kg} /$ day was found to adequately fit the observed data.

The following shows examples of 'predicted' population average concentrations. The following 11 modeled body lipid concentrations of TEQs in $\mathrm{pg} / \mathrm{g}$ lipid characterize average adult populations in 1985 and 1995 (these were modeled using the final calibrated and assigned model parameters):

\begin{tabular}{ccccccccccccc} 
Age $\rightarrow$ & 20 & 25 & 30 & 35 & 40 & 45 & 50 & 55 & 60 & 65 & 70 & Average population \\
\hline 1985 & 26 & 34 & 40 & 45 & 48 & 51 & 54 & 56 & 59 & 61 & 63 & 48 pg TEQ/g lipid \\
1995 & 11 & 14 & 19 & 23 & 27 & 30 & 32 & 35 & 38 & 40 & 43 & 28 pg TEQ/g lipid
\end{tabular}

These average population predictions were compared to the measured population body burdens shown in Table 1 and described above. The final calibrated dose function, $e(t)$, is shown in Fig. 6. Also identified in this figure is EPA's estimate of current intake of PCDD/PCDF TEQs, $0.65 \mathrm{pg} /$ $\mathrm{kg}$ /day (US EPA, 2000). 


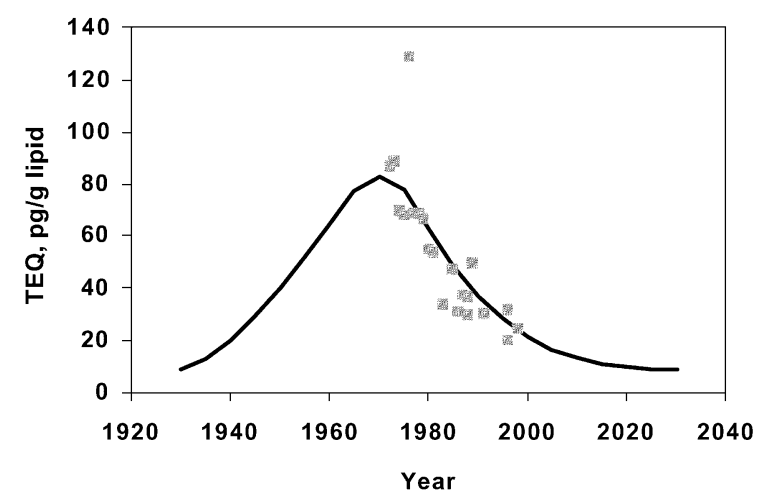

Fig. 7. Predicted adult population body concentration of TEQs, $\mathrm{pg} / \mathrm{g}$ lipid (solid lines) compared against the measured population body concentrations of TEQs, pg/g lipid (squares).

\section{Results and discussions}

Average predicted population lipid TEQ concentrations in 5-year increments from 1930 to 2030 were connected by the solid line shown in Fig. 7 . The observations from the 12 literature studies are shown as dots in Fig. 7. Besides observing what appears to be a good fit between observed and predicted population average body lipid TEQ concentrations over time, no statistical goodness-of-fit tests were conducted.

Trends in past and future exposures can be hypothesized from this framework. For example, Fig. 6 suggests that peak TEQ doses were above $6.0 \mathrm{pg}$ TEQ/ kg/day during the $1960 \mathrm{~s}$ and $1970 \mathrm{~s}$, which is 10 times higher than current doses recently estimated to be $0.65 \mathrm{pg}$ TEQ $/ \mathrm{kg} /$ day. According to Fig. 7, current body concentrations at approximately 20 ppt TEQ could fall to below 10 ppt TEQ by 2020 or thereabouts assuming intakes now stay constant at approximately $0.50 \mathrm{pg}$ TEQ/ $\mathrm{kg} /$ day.

This framework is also useful in studying trends in population and individual body burdens. One trend that has often been found in cross-sectional surveys during the 1980s and 1990s is an 'age trend,' that older individuals have higher body burdens than younger individuals. Figs. 8 and 9 show individual measurements that were available for two of the population surveys - one from Missouri in 1985 (Graham et al., 1986) and a



Fig. 8. Comparison of predicted (solid line with circles) and observed body concentrations of TEQs (diamonds, from Graham et al., 1986) for the year 1985.

subset of the Centers for Disease Control (CDC) compilation from several sites in 1996 (personal communication from D. Patterson, Center for Disease Control, Atlanta, GA, USA, to M. Lorber, US EPA, Washington, DC, USA, April, 2000). Superimposed on results for individuals in these surveys are the modeled population prediction corresponding to years 1985 and 1995 (these were the 2 years demonstrated above in the calibration section). In Fig. 8, the measured body burdens in the St. Louis site ranged from approximately 15 to $140 \mathrm{pg}$ TEQ/g lipid, with an average of $47 \mathrm{pg}$ TEQ/g lipid. The predicted body burdens as a function of age appear to match this population fairly well, with a nearly identical average of 49

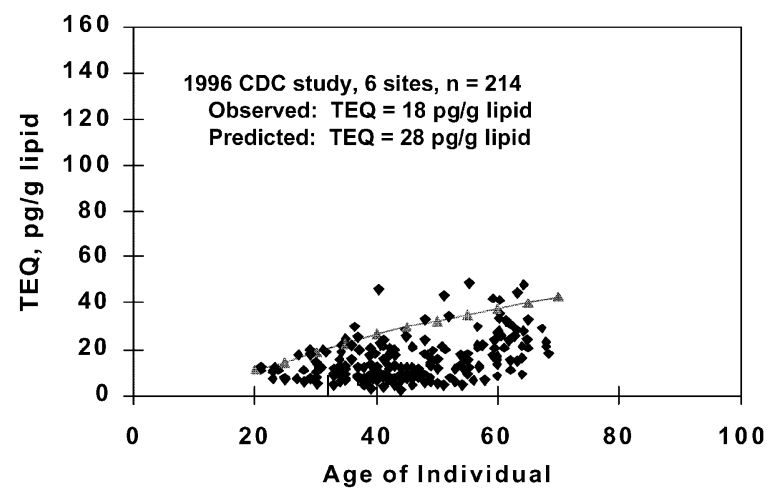

Fig. 9. Comparison of predicted (solid line with triangles) and observed body concentrations of TEQs (diamonds, from Centers for Disease Control data) for the year 1995. 
pg TEQ/g lipid. Fig. 9 shows a subset of the1996 CDC data set, including only those samples where there was information on age. Of the sub-populations in the CDC compilation, individual agespecific data was not available for the Wisconsin data set, $n=93$, who had the highest average body burden at $26 \mathrm{pg}$ TEQ/g lipid. The data for the 214 individuals had a smaller range and average body burden at $18 \mathrm{pg}$ TEQ/g lipid. In any case, the modeled age trend was somewhat more exaggerated than was measured, with a more steeply inclining trend with age and an average of $28 \mathrm{pg}$ TEQ/g lipid.

While this age trend may have been present during the 1980s and 1990s, it may not have been present before these dates and may not be present in the future. Fig. 10 shows the age trend for the year 1965 as well as the year 2030, along with the results from 1985 and 1995. In 1965, the population had all been experiencing the ongoing rising high exposures, and the adult average body burden from age 20 to 70 ranged narrowly from 72 to 78 pg TEQ/g lipid. By 2030, all the population had been experiencing the low constant dose of 0.50 pg TEQ/kg/day. There is a slight age trend due to the long half-lives assumed for TEQs, but the range is reasonably narrow from 7 to 12 pg TEQ/ g lipid.

The 'age effect' is not necessarily a trend within an individual, however, as seen in Fig. 11. In this



Fig. 11. Predictions of an individual's body TEQ concentration from ages 10 to 70 as a function of birth year.

figure, the time trend in an individual's body burden is displayed. Body burdens are predicted to peak during the time when doses were high, from the 1940s to the 1970s. If that period falls late within a persons life, e.g. those born in 1910, then the body burdens are highest late in life, or their body burdens could be highest earlier in life if they were born near the end of that period. These results suggest that individuals born around 1950 have been in a state of depuration for the past three decades and their body burdens are continuing to decline today.

The principal uncertainties that can be identified for this effort include: (1) that a one-compartment,



Fig. 10. Predicted distributions of and average TEQ concentrations within an adult population for 4 years: 1965, 1985, 1995, and 2030 . 
first-order model adequately describes the accumulation of TEQs intakes in humans; (2) that a TEQ body burden can be adequately modeled in this framework with a single elimination rate function which, in this paper, was calibrated; and (3) that the measured body burden data collected for this effort adequately describe the general adult population during the 1970s, 1980s, and 1990s. Given these uncertainties, one must be cautious in the derivation of conclusions. Still, this framework has been developed and used to study past, present, and future trends in exposure of Americans to dioxin TEQs.

Future efforts could focus on the use of more complex physiologically-based models such as those of Van der Molen et al. (1996) and development of age/elimination rate functions for individual congeners. It might also be interesting to locate repositories for human tissue samples in earlier decades of the 20th century, from blood banks, hospitals, or similar facilities, and to possibly study temporal trends in body burdens of dioxin-like compounds more systematically.

\section{Disclaimer}

The views expressed in this article are those of the author and do not necessarily reflect the views or policies of the US Environmental Protection Agency.

\section{References}

Alcock RE, Coleman P, McLachlan M, Johnston AE, Jones KC. Reconstructing air concentrations and deposition fluxes of PCDD/Fs in the UK. Organohalogen Compd 1997;33:88.

Cleverly D, Monetti M, Phillips L, Cramer P, Heit M, McCarthy S, O'Rourke K, Stanley J, Winters D. A time-trends study of the occurrences and levels of CDDs, CDFs and dioxin-like PCBs in sediment cores from 11 geographically distributed lakes in the United States. Organohalogen Compd 1996;28:77.

Czuczwa JM, Hites RA. Environmental fate of combustiongenerated polychlorinated dioxins and furans. Environ Sci Technol 1984;18:444.

Czuczwa JM, McVeety BD, Hites RA. Polychlorinated dibenzo- $p$-dioxins and dibenzofurans in sediments from Siskiwit Lake, Isle Royale. Chemosphere 1985;14:623.

Flesch-Janys D, Becher H, Gurn P, Jung D, Konietzko J, Manz A, Popke O. Elimination of polychlorinated dibenzo- $p$ - dioxins and dibenzofurans in occupationally exposed persons. J Toxicol Environ Health 1996;47:363.

Fürst P, Wilmers K. PCDD/F levels in dairy products 1994 versus 1990. Organohalogen Compd 1995;26:101.

Graham M, Hileman FD, Orth RG, Wendling JM, Wilson JD. Chlorocarbons in adipose tissue from a Missouri Population. Chemosphere 1986;15:1595.

Harrison N, Wearne S, de M, Gem MG, Gleadle A, Startin J, Thorpe S, Wright C, Kelly M, Robinson C, White S, Hardy $\mathrm{D}$, Edinburgh V. Time trends in human dietary exposure to PCDDs, PCDFs and PCBs in the UK. Chemosphere 1998;37:1657.

Kang HK, Watanabe KK, Breen J, Remmers J, Conomos MG, Stanley J, Flicker M. Dioxins and dibenzofurans in adipose tissue of US Vietnam veterans and controls. Am J Public Health 1991;81:344.

Lakind JS, Berlin CM, Park CN, Naiman DQ, Gudka NJ. Methodology for characterizing distributions of incremental body burdens of 2,3,7,8-TCDD and DDE from breast milk in North American nursing infants. J Toxicol Environ Health 2000;59:605.

Michalek JE, Pirkle JL, Caudill SP, Tripathi RC, Patterson DG, Needham LL. Pharmacokinetics of TCDD in veterans of operation Ranch Hand: 10-year follow up. J Toxicol Environ Health 1996;47:209.

Orban JE, Stanley JS, Schwember JG, Remmers JC. Dioxins and dibenzofurans in adipose tissue of the general US population and selected subpopulations. Am J Public Health 1994;84:439.

Patterson DG, Todd GD, Turner WE, Maggio V, Alexander LR, Needham LL. Levels of non-ortho-substituted (coplanar), mono- and di-ortho-substituted polychlorinated biphenyls, dibenzo- $p$-dioxins, and dibenzofurans in human serum and adipose tissue. Environ Health Perspect Suppl 1994;102(suppl 1):195.

Petreas M, She J, Winkler J, Visita P, McKinney M, Reynolds P, Smith D, Gilliss D, Hurley S, Jeffrey S, Mahoney E. Body burdens of organohalogens in California populations. Organohalogen Compd 2000;48:17.

Pinsky P, Lorber MN. A model to evaluate past exposure to 2,3,7,8-TCDD. J Exposure Anal Environ Epidemiol 1998;8:187.

Schecter A, Ryan JJ, Gitlitz G. Chlorinated dioxin and dibenzofuran levels in human adipose tissues from exposed and control populations. Chapter 4, p. 51-65. In: Rappe C, et al, editor. Chlorinated Dioxins and Dibenzofurans in Perspective. Chelsea, Michigan: Lewis Publishing, 1986.

Schecter A, Constable J, Bangert JV, Wiberg K, Hansson M, Nygren M, Rappe C. Isomer specific measurement of polychlorinated dibenzodioxin and dibenzofuran isomers in human blood from American veterans two decades after exposure to Agent Orange. Chemosphere 1989;18:531.

Schecter A. Dioxins and related chemicals in humans and in the environment. p. 169-212. In: Gallo MA, Scheuplein RJ, van der Heijden CA, editors. Biological Basis for Risk Assessment of Dioxins and Related Compound. New York: Cold Spring Harbor Laboratory Press, 1991:169-212. 
Schecter A, McGee H, Stanley J, Boggess K. Chlorinated dioxin, dibenzofuran, coplanar, mono-ortho, and di-ortho substituted PCB congener levels in blood and semen of Michigan Vietnam veterans compared with levels in Vietnamese exposed to Agent Orange. Chemosphere 1993;27:241.

Schecter A, Papke O, Furst P, Ryan JJ. Temporal changes in dioxin and dibenzofuran levels in general population human blood and milk from Germany and the United States. Organohalogen Compd 1997;33:473.

Smith RM, O'Keefe P, Aldous K, Briggs R, Hilker D, Connor $\mathrm{S}$. Measurement of PCDFs and PCDDs in air samples and lake sediments at several locations in upstate New York. Chemosphere 1992;25:95.

Smith RM, O'Keefe PW, Hilker DR, Bush B, Connor S, Donnelly R, Storm R, Liddle M. The historical record of PCDDs, PCDFs, PAHs, PCBs, and lead in Green Lake, New York - 1860 to 1990. Organohalogen Compd 1993;20:215.

Smith RM, O'Keefe PW, Hilker D, Connor S, Posner E. Direct and indirect contributions of atmospheric PCDDs and PCDFs to Hudson River national estuarine research reserve sediment cores. Organohalogen Compd 1995;24:141.

Stanley JS, Bauer KM, Turman K, Boggess K, Cramer P. Determination of body burdens for polychlorinated dibenzo$p$-dioxins (PCDDs) and polychlorinated dibenzofurans (PCDFs) in California residents. Final Report for the State of California Air Resources Board, Research Division, 1800 15th St, Sacramento, CA 95812. ARB Contract NoA6-19533. 1989.

US EPA (Environmental Protection Agency), Dioxins and Dibenzofurans in Adipose Tissue of U.S. Vietnam veterans and Controls. Department of veterans Affairs and the U.S. EPA. 1990. EPA-560/5-89-002.

US EPA (Environmental Protection Agency), Chlorinated dioxins and furans in the General U.S. Population: NHATS
FY87 Results. Office of Toxic Substances, U.S. EPA. 1991. EPA-560/5-91/003.

US EPA (Environmental Protection Agency), Exposure and Human Health Reassessment of 2,3,7,8-Tetrachlorodibenzo$p$-Dioxin (TCDD) and Related Compounds. National Center for Environmental Assessment, Office of Research and Development, U.S. EPA. Review Draft. September, 2000. EPA/600/P-00/001B(a-f). Available at, http:// cfpub1.epa.gov $/$ ncea $/ \mathrm{cfm} /$ nceahome.cfm.

United States Environmental Protection Agency. Exposure Factors Handbook, National Center for Environmental Assessment, Office of Research and Development, US EPA. 1997. EPA/600/P-95/002F(a-c). 1997.

Van den Berg ML, Birnbaum L, Bosveld ATC, Brunstrom B, Cook P, Feeley M, Giesy JP, Hanberg A, Hasegawa R, Kennedy SW, Kubiak T, Larsen JC, van Leeuwen FXR, Liem AKD, Nolt C, Peterson RE, Poellinger L, Safe S, Schrenk D, Tillitt D, Tysklind M, Younes M, Warn F, Zacharewski T. Toxic Equivalency Factors (TEFs) for PCBs, PCDDs, PCDFs for Humans and Wildlife. Environmental Health Perspectives 1998;106:775.

Van der Molen GW, Kooijman SALM, Slob W. A generic toxicokinetic model for persistent lipophilic compounds in humans: an application to TCDD. Fund Appl Toxicol 1996;31:83.

Van der Molen GW, Kooijman SALM, Michalek JE, Slob W. The estimation of elimination rates of persistent compounds: a re-analysis of 2,3,7,8-tetrachlorodibenzo- $p$-dioxin levels in Vietnam veterans. Chemosphere 1998;37:1833.

Van der Molen GW, Kooijman BALM, Wittsiepe J, Schrey P, Flesch-Janys D, Slob W. Estimation of dioxin and furan elimination rates with a pharmacokinetic model. J Expos Anal Environ Epidemiol 2000;10:579.

Winters DL, Anderson S, Lorber M, Ferrario J, Byrne C. Trends in dioxin and PCB concentrations in meat samples from several decades of the 20th century. Organohalogen Compd 1998;38:75. 